\title{
Aspirin-tolerant asthmatics generate more lipoxins than aspirin-intolerant asthmatics
}

\author{
M. Sanak*, B.D. Levy\#, C.B. Clish ${ }^{\#}$, N. Chiang ${ }^{\#}$, K. Gronert", L. Mastalerz*, \\ C.N. Serhan", A. Szczeklik*
}

Aspirin-tolerant asthmatics generate more lipoxins than aspirin-intolerant asthmatics. $M$. Sanak, B.D. Levy, C.B. Clish, N. Chiang, K. Gronert, L. Mastalerz, C.N. Serhan, A. Szczeklik. (C) ERS Journals Ltd 2000.

ABSTRACT: Asthma is characterized by chronic airway inflammation resulting from overproduction of pro-inflammatory mediators, such as leukotrienes (LT). The authors questioned the biosynthetic capacity of asthmatic patients for lipoxins (LX) and 15-epimer lipoxins (15-epi-LX), endogenous regulators of inflammatory responses that inhibit pro-inflammatory events.

Levels of $\mathrm{LXA}_{4}, 15$-epi-LXA $\mathrm{A}_{4}$ and $\mathrm{LTC}_{4}$ were determined in 14 clinically characterized aspirin-intolerant asthmatics (AIA), 11 aspirin-tolerant asthmatics (ATA) and eight healthy volunteers using a stimulated whole blood protocol.

Both $\mathrm{LXA}_{4}$ and 15-epi-LXA $\mathrm{AS}_{4}$ were generated in whole blood activated by the divalent cation ionophore, A23187. Higher levels of $\mathrm{LXA}_{4}$ were produced in ATA than either AIA or healthy volunteers. Exposure of AIA whole blood to interleukin-3 prior to $\mathbf{A 2 3 1 8 7}$ did not elevate their reduced capacity to generate $\mathrm{LXA}_{4}$. Generation of a bronchoconstrictor, $\mathrm{LTC}_{4}$, was similar in both AIA and ATA. Consequently, the ratio of $\mathrm{LXA}_{4}: \mathrm{LTC}_{4}$ quantitatively favoured the bronchoconstrictor for AIA and differed from both ATA and healthy subjects. In addition, the capacity for 15-epi-LXA generation was also diminished in AIA, since whole blood stimulated in the presence of aspirin gave increased levels only in samples from ATA.

The present results indicate that asthmatics possess the capacity to generate both lipoxins and 15-epimer-lipoxins, but aspirin-intolerant asthmatics display a lower biosynthetic capacity than aspirin-tolerant asthmatics for these potentially protective lipid mediators. This previously unappreciated, diminished capacity for lipoxin formation by aspirin-intolerant asthmatic patients may contribute to their more severe clinical phenotype, and represents a novel paradigm for the development of chronic inflammatory disorders.

Eur Respir J 2000; 16: 44-49.

*Dept of Medicine, Jagellonian University School of Medicine, Kraków, Poland. ${ }^{\#}$ Center for Experimental Therapeutics and Reperfusion Injury, Dept of Anesthesiology, Perioperative and Pain Medicine, Brigham and Women's Hospital, Harvard Medical School, Boston, MA, USA. ${ }^{*}{ }^{*} \mathrm{M}$. Sanak and B.D. Levy contributed equally.

Correspondence: C.N. Serhan, Center for Experimental Therapeutics and Reperfusion Injury, Thorn Building for Medical Research, Room 724, Brigham and Women's Hospital, 75 Francis Street, Boston MA 02115 USA. Fax: 16172786957

Keywords: Anti-inflammatory mediators, aspirin-intolerant asthma, cysteinyl-leukotrienes, lipoxins

Received: October 251999

Accepted after revision April 32000

This work has been supported in part by the National Institutes of Health Scientist Exchange Program under a bilateral agreement between the NHLBI and the National Institute of Cardiology, Warsaw, Poland to M. Sanak and C.N. Serhan, National Institutes of Health grants HL56383, GM-38765 to C.N. Serhan, NHLBI-K08-HL03788 to B.D. Levy, and by the Polish State Research Council Grant 4POSB09514 to A. Szczeklik.
Aspirin (acetylsalicylic acid)-intolerance is a distinct clinical syndrome observed in 5-10\% of adult patients with asthma $[1,2]$. In these patients, aspirin and several other nonsteroidal anti-inflammatory drugs (NSAIDs) that inhibit cyclo-oxygenase (COX) precipitate asthmatic attacks. Despite avoidance of NSAIDs, aspirin-intolerant asthmatics (AIA) experience protracted symptoms with many requiring systemic corticosteroids for control. This syndrome's pathophysiology is characterized in part by excess production of cysteinyl (Cys)-leukotrienes (LT), such as $\mathrm{LTC}_{4}$ and $\mathrm{LTD}_{4}[3-5]$, which primarily serve as bronchoconstrictors [6] as well as pro-inflammatory mediators [7]. Bronchial biopsies of asthmatic airways reveal marked accumulation of eosinophils [8] and overexpression of $\mathrm{LTC}_{4}$ synthase [9], the terminal enzyme for Cys-LT production. Drugs that prevent the formation or action of Cys-LT effectively prevent aspirin-precipitated attacks of asthma $[7,10]$ and, on prolonged administration, improve control of the disease [11].

Lipoxins (LX) and 15-epimer-lipoxins (15-epi-LX) are also lipoxygenase (LO)-derived eicosanoids, yet their biological actions differ dramatically from LT [12]. In sharp contrast to LT, LX inhibit bronchoconstriction [13] and carry local anti-inflammatory signals [14]. LX possess a distinctive trihydroxytetraene structure, and are produced by transcellular biosynthesis during cell-cell interactions (e.g. between infiltrating leukocytes and resident cells) that occur in pathological states [14], such as in human airways $[15,16]$ and nasal polyps [17]. $\mathrm{LXA}_{4}$ inhibits polymorphonuclear neutrophil (PMN) and eosinophil chemotaxis $[18,19]$ and PMN transmigration into inflammatory tissues [14], responses of interest in airway disease. Of particular interest, inhalation of $\mathrm{LXA}_{4}$ by human asthmatics blocks $\mathrm{LTC}_{4}$ stimulated bronchoconstriction [13]. Thus, LX formation in the human lung may, in view of LX actions, play a role in airway disease.

Recently, a novel mechanism of action was uncovered for aspirin revealing that, when inhibiting prostaglandin formation, aspirin-acetylated COX-2 can participate in the generation of new endogenous lipid mediators that are the carbon 15-epimers of LX [20]. These "aspirin-triggered" 15-epi-LX share LX bioactions, are potent counter-regulatory lipid mediators that block LT-mediated inflammatory responses in vivo and can compete for $\mathrm{LTD}_{4}$ specific binding [21]. Thus, formation of 15-epi-LX within the local inflammatory milieu may represent a novel molecular 
mechanism underlying some of aspirin's salutary effects. In the present study, the authors questioned whether aspirintolerant and aspirin-intolerant asthmatic patients, who develop chronic airway inflammation, can generate both LX and the aspirin-triggered 15-epi-LX.

\section{Methods}

\section{Study subjects}

Between December 1997 and June 1998, 14 AIA and 11 aspirin-tolerant asthmatics (ATA) who presented consecutively to one of the authors (A. Szczeklik) at the Dept of Medicine at Jagellonian University in Kraków, Poland were prospectively enrolled for the study. The diagnosis of aspirin intolerance was confirmed by aspirin provocation tests [22] performed during the 12 months directly preceding the study. In addition, ATA patients reported use of NSAIDs without adverse effects. All patients were nonsmokers, in stable clinical condition and not using systemic anti-inflammatory drugs during the study (table 1).

\section{Study design}

After stimulation of each subject's whole blood, duplicate determinations of plasma levels of $\mathrm{LXA}_{4}, 15$-epi-LXA and $\mathrm{LTC}_{4}$ were performed using specific enzyme-linked immunosorbent assays (ELISA) in tandem (Neogen Corp., Lexington, KY, USA and Cayman Chemical, Co., Ann Arbor, MI, USA). The $\mathrm{LXA}_{4}$ and 15-epi-LXA 4 ELISAs were validated for these experiments by physical methods, including high-performance liquid chromatography (HPLC) and liquid chromatography/tandem mass spectrometry (LC/MS/MS) $[16,23]$. Here, the identities of the immunoreactive eicosanoids were confirmed using LC/ $\mathrm{MS} / \mathrm{MS}$

\section{Methods}

Peripheral venous blood $(\sim 15 \mathrm{~mL})$ was obtained by venepuncture from volunteer subjects who had given written informed consent to a protocol approved by the Jagellonian University Ethical Committee (Kraków, Poland). Blood samples were drawn into three standard $5 \mathrm{~mL}$ tubes

Table 1. - Characteristics of subjects

\begin{tabular}{lccc}
\hline & $\begin{array}{c}\text { Healthy } \\
\text { volunteers }\end{array}$ & $\begin{array}{c}\text { Aspirin } \\
\text {-tolerant } \\
\text { asthmatics }\end{array}$ & $\begin{array}{c}\text { Aspirin } \\
\text {-intolerant } \\
\text { asthmatics }\end{array}$ \\
\hline Subjects n & 10 & 11 & 14 \\
Age yrs & $43.8 \pm 6.5$ & $45.7 \pm 9.5$ & $47.6 \pm 9.6$ \\
Male/female & $4 / 6$ & $3 / 8$ & $8 / 6$ \\
Duration of asthma yrs & $\mathrm{NA}$ & $10.4 \pm 8.9$ & $8.0 \pm 4.8$ \\
Leukocyte cells $\cdot \mathrm{mm}^{-3}$ & $\mathrm{NM}$ & $6440 \pm 160$ & $6490 \pm 1200$ \\
Eosinophils cells $\cdot \mathrm{mm}^{-3}$ & $\mathrm{NM}$ & $215 \pm 150$ & $279 \pm 138$ \\
Platelets cells $\cdot \mathrm{mm}^{-3}$ & $\mathrm{NM}$ & 234500 & 247200 \\
& & \pm 69800 & \pm 53030 \\
FEV1 L & $\mathrm{NM}$ & $2.70 \pm 0.73$ & $2.72 \pm 0.61$ \\
FEV1 \% & $\mathrm{NM}$ & $92.4 \pm 13.4$ & $86.4 \pm 11.7$ \\
Total IgE IU $\cdot \mathrm{mL}^{-1}$ & $55.2 \pm 72.2$ & $91.3 \pm 215.9$ & $58.6 \pm 82.5$ \\
Inhaled steroids $\%$ & 0 & 78 & 65 \\
\hline
\end{tabular}

Values are the mean \pm SD. NA: not applicable; NM: not measured FEV1: forced expiratory volume in one second; IgE: immunoglobulinE. *: geometric mean \pm SD. containing sodium heparin (Vacutainer; Becton Dickinson, Franklin Lakes, NJ, USA) and processed immediately. Whole blood samples were exposed $\left(37^{\circ} \mathrm{C}, 30 \mathrm{~min}\right.$ with gentle shaking (40 rpm) in a vertical position) to recombinant human interleukin (IL)-3 (20 ng.mL; Genzyme, Cambridge, MA, USA) in the presence (tube 1) or absence (tube 2) of lysyl-aspirin $(100 \mu \mathrm{M})$ followed by activation (45 $\mathrm{min}, 37^{\circ} \mathrm{C}$ ) with the divalent cation ionophore, A23187 ( $50 \mu \mathrm{M}$; Sigma Chemical Co., St. Louis, MO, USA). Note that this concentration of A23187 is required to activate eicosanoid generation in whole blood [24]. The third blood sample was not exposed to IL-3 and warmed $\left(37^{\circ} \mathrm{C}, 5 \mathrm{~min}\right)$ directly prior to activation. After stimulation, plasma was separated from blood by centrifugation $\left(3,000 \times g, 10 \mathrm{~min}, 25^{\circ} \mathrm{C}\right)$ and stored at $-80^{\circ} \mathrm{C}$ until eicosanoid levels were measured by ELISA.

Samples of plasma from several donors were pooled to obtain quantities that permitted physical identification and $10 \mathrm{ng}$ of deuterium-labelled $\mathrm{LTB}_{4}\left(\mathrm{~d}_{4}-\mathrm{LTB}_{4}\right.$; Cayman Chemical Co.) was added as an internal standard. Eicosanoids were extracted as in LEVY et al. [25] and methyl formate fractions obtained from these samples were taken to LC/MS/MS for analysis of LX and other eicosanoids [25]. The stereochemistry of 15 -hydroxyeicosatetraenoic acid (15-HETE) (\% $R$ versus $S$ epimer) was determined by chiral HPLC [25].

\section{Analysis}

Samples were coded so that patient identities were not revealed. Collected data were analysed for significance using an unpaired t-test that was performed with statistical software (Microsoft Excel, version 97 SR-1; Microsoft Corp., Redmond, WA, USA). Probability values were twotailed, with $\mathrm{p}<0.05$.

\section{Results}

\section{Patient characteristics}

Characteristics of the subjects on enrolment are presented in table 1. Although peripheral blood eosinophilia was more pronounced in AIA $(($ mean \pm SD $) 279 \pm$ $\left.138 \cdot \mathrm{mm}^{-3}\right)$ than ATA $\left(215 \pm 150 \cdot \mathrm{mm}^{-3}\right)$, there was no statistical difference. In addition, the asthmatics had no statistical differences with respect to age, duration of asthma, cell counts, baseline spirometry, serum total immunoglobulin E or treatment. At the time of sample acquisition, asthma symptoms were well-controlled in all subjects and none were taking oral glucocorticoids.

\section{Lipoxin and 15-epimer-lipoxin biosynthetic capacity}

Activated whole blood from AIA patients produced $\mathrm{LXA}_{4}$ in amounts that were not statistically different from that generated by healthy volunteers $(($ mean \pm SEM $) 5.7 \pm 2.0$ versus $7.2 \pm 2.8 \mathrm{ng} \cdot \mathrm{mL}^{-1}$ ). This observation contrasts with the LX biosynthetic capacity of ATA whole blood that generated approximately two-fold more $\mathrm{LXA}_{4}\left(12.9 \pm 5.4 \mathrm{ng} \cdot \mathrm{mL}^{-1}\right)$ than that from AIA $\left(5.7 \pm 2.0 \mathrm{ng} \cdot \mathrm{mL}^{-1}\right)$. The addition of exogenous substrate was not required for either $\mathrm{LXA}_{4}$ or 15 epi-LXA ${ }_{4}$ formation in activated whole blood, indicating that both ATA and AIA utilized endogenous sources of arachidonate to generate these counterregulatory eicosanoids. 
IL-3 is elaborated by helper type 2 lymphocytes and held to be a pro-inflammatory cytokine that increases the generation of eicosanoids by stimulated granulocytes [26]. Here, the addition of IL-3 increased $\mathrm{LXA}_{4}$ from 7.2 to $12.1 \mathrm{ng} \cdot \mathrm{mL}^{-1}$ in activated whole blood from healthy volunteers. In contrast, neither ATA nor AIA whole blood gave increased LX biosynthetic capacity when exposed to IL-3 and thus these two asthma cohorts still showed a difference in $\mathrm{LXA}_{4}$ generation when a stimulatory cytokine was present (fig. 1a).

$\mathrm{LTC}_{4}$ was present in all samples following activation of whole blood (range: 0.26-3.3; median 1.2; mean 1.4 $\left.\mathrm{ng} \cdot \mathrm{mL}^{-1}\right)$. The levels of $\mathrm{LTC}_{4}$ in AIA and ATA samples did not differ $\left((\right.$ mean $\pm \mathrm{SEM}) 1.4 \pm 0.2$ versus $\left.1.4 \pm 0.2 \mathrm{ng} \cdot \mathrm{mL}^{-1}\right)$. Moreover, the relationship between LX and LT production, expressed as the ratio of $\mathrm{LXA}_{4}$ to $\mathrm{LTC}_{4}$, was significantly reduced in AIA below that observed with either ATA or healthy subjects (fig. 1b).

In addition to $\mathrm{LXA}_{4}$, activated whole blood also generated 15-epi-LXA 4 (fig. 2). When activated in the presence of aspirin, values for 15-epi-LXA $\mathrm{LX}_{4}$ increased $\sim 80 \%$ in ATA whole blood (1.4 to $\left.2.6 \mathrm{ng} \cdot \mathrm{mL}^{-1}\right)$. In contrast to the response in ATA, neither 15-epi-LXA 4 nor $\mathrm{LXA}_{4}$ formation were increased in aspirin-treated samples from AIA, and together, their sum $\left(4.5 \mathrm{ng} \cdot \mathrm{mL}^{-1}\right)$ was significantly less than in ATA ((mean) $\left.11.1 \mathrm{ng} \cdot \mathrm{mL}^{-1}, \mathrm{p}<0.05\right)$. The
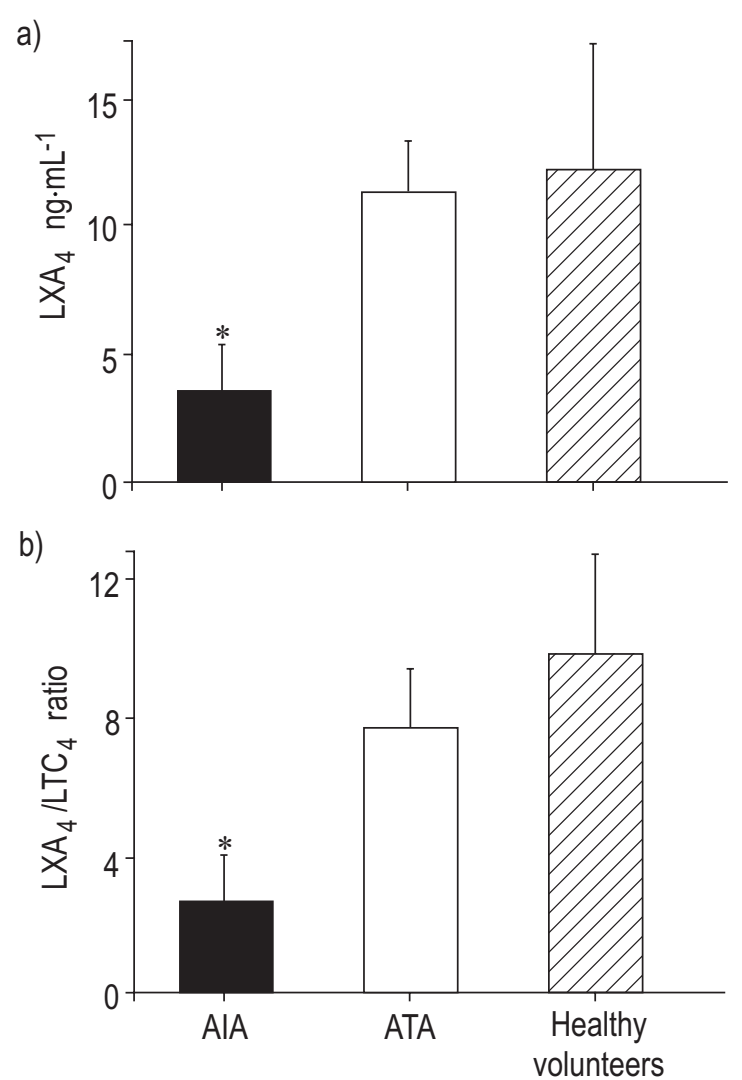

Fig. 1. - Diminished lipoxin (LX)A $\mathrm{A}_{4}$ biosynthetic capacity in aspirinintolerant asthmatics (AIA). Whole blood samples from AIA or aspirintolerant asthmatics (ATA) were exposed to interleukin-3 $\left(20 \mathrm{ng} \cdot \mathrm{mL}^{-1}, 30\right.$ $\min , 37^{\circ} \mathrm{C}$ ) and activated (see Methods section) $\left(45 \mathrm{~min}, 37^{\circ} \mathrm{C}\right)$ as in [24]. $\mathrm{LXA}_{4}$ and leukotriene (LT) $\mathrm{C}_{4}$ were measured by specific enzyme linked immunosorbent assays in tandem. Values for $\mathrm{LXA}_{4}$ (a) and the ratio of $\mathrm{LXA}_{4}$ : $\mathrm{LTC}_{4}$ (b) represent the mean \pm SEM for $\mathrm{n}=11$ (ATA), $\mathrm{n}=14$ (AIA) and $\mathrm{n}=8$ (healthy volunteers). ${ }^{*}: \mathrm{p}<0.05$ by unpaired $t$-test. levels of both $\mathrm{LXA}_{4}$ and 15-epi-LXA 4 generated in whole blood were decreased in AIA compared to ATA (fig. 2). These findings indicate that whole blood from both ATA and AIA can generate 15 -epi-LXA 4 , but the biosynthetic capacity for 15-epi-LX is lower in whole blood from AIA patients.

To further validate the identification of these potential anti-inflammatory eicosanoids, samples from each patient group were pooled and analysed by LC/MS/MS for identification of retention times, signature ions and diagnostic product ion mass spectrometry (MS/MS) spectra. Both $\mathrm{LXA}_{4}$ and $\mathrm{LXB}_{4}$ were present in each study group. Native $\mathrm{LXA}_{4}$ and its all-trans isomer (11-trans-LXA ${ }_{4}$ ) eluted at 15.0 and $12.7 \mathrm{~min}$ (consistent with authentic synthetic materials), respectively, and were further identified on the basis of their molecular anions ([M-H $]^{-}$mass-to-change ratio $(\mathrm{m} /$ z) 351) and diagnostic product ions present in their corresponding MS/MS spectra (fig. 3). Prominent diagnostic ions for $\mathrm{LXA}_{4}$ were identified at $m / z 333\left([\mathrm{M}-\mathrm{H}]^{-}-\mathrm{H}_{2} \mathrm{O}\right)$, $m / z 315\left([\mathrm{M}-\mathrm{H}]^{-}-2 \mathrm{H}_{2} \mathrm{O}\right), m / z 307\left([\mathrm{M}-\mathrm{H}]^{-}-\mathrm{CO}_{2}\right), m / z 289$ ([M-H] $\left.]^{-}-\mathrm{H}_{2} \mathrm{O},-\mathrm{CO}_{2}\right), m / z 251\left([\mathrm{M}-\mathrm{H}]^{-}-\mathrm{CHO}\left(\mathrm{CH}_{2}\right)_{4} \mathrm{CH}_{3}\right)$, $\mathrm{m} / \mathrm{z} 233\left([\mathrm{M}-\mathrm{H}]^{-}-\mathrm{H}_{2} \mathrm{O},-\mathrm{CHO}\left(\mathrm{CH}_{2}\right)_{4} \mathrm{CH}_{3}\right), \mathrm{m} / z 135\left(\left[\mathrm{CH}_{2}\right.\right.$ $\left.\mathrm{CH}(\mathrm{CH}=\mathrm{CH})_{3} \mathrm{CHOH}^{-}\right)$, and $\mathrm{m} / z 115\left(\mathrm{CHO}\left(\mathrm{CH}_{2}\right)_{3}\right.$ $\mathrm{COO}^{-}$). Native $\mathrm{LXB}_{4}$ and its all-trans isomer (8-trans$\mathrm{LXB}_{4}$ ) were eluted at 10.9 and $9.8 \mathrm{~min}$, respectively, and were also identified on the basis of their molecular anions $\left([\mathrm{M}-\mathrm{H}]^{-}=m / z 351\right)$ and diagnostic product ions in their MS/ MS spectra (fig. 3) occurring at $m / z 333$ ([M-H $]^{-}-\mathrm{H}_{2} \mathrm{O}$ ), $m / z$ $315\left([\mathrm{M}-\mathrm{H}]^{-}-2 \mathrm{H}_{2} \mathrm{O}\right), m / z 307\left([\mathrm{M}-\mathrm{H}]^{-}-\mathrm{CO}_{2}\right), m / z 289$ ([M$\left.\mathrm{H}^{-}-\mathrm{H}_{2} \mathrm{O},-\mathrm{CO}_{2}\right), m / z 271\left([\mathrm{M}-\mathrm{H}]^{-}-2 \mathrm{H}_{2} \mathrm{O},-\mathrm{CO}_{2}\right), m / z 251$ $\left([\mathrm{M}-\mathrm{H}]^{-}-\mathrm{CHO}\left(\mathrm{CH}_{2}\right)_{4} \mathrm{CH}_{3}\right), m / z 233\left([\mathrm{M}-\mathrm{H}]^{-}-\mathrm{H}_{2} \mathrm{O},-\mathrm{CHO}\right.$ $\left.\left(\mathrm{CH}_{2}\right)_{4} \mathrm{CH}_{3}\right)$, and $m / z 221\left([\mathrm{M}-\mathrm{H}]^{-}-\mathrm{CHOCHOH}\left(\mathrm{CH}_{2}\right)_{4}\right.$ $\left.\mathrm{CH}_{3}\right)$. LC/MS/MS analysis revealed a ratio for $\mathrm{LXA}_{4}$ : $\mathrm{LXB}_{4}$ generation of $\sim 1.2: 1$. (Note: $\mathrm{LXB}_{4}$ and, its aspirintriggered epimeric form, 15-epi-LXB $\mathrm{LX}_{4}$ levels were not monitored in individual samples because the authors have not yet prepared immunoassays for these eicosanoids.)

In addition to both $\mathrm{LXA}_{4}$ and $\mathrm{LXB}_{4}, 15 \mathrm{~S}$-HETE (stereochemistry at the carbon 15 alcohol was determined by chiral HPLC analysis) was also present in samples from patients with AIA. Patient-derived 15-HETE was eluted at 37.9 min (consistent with authentic 15S-HETE in this LC/

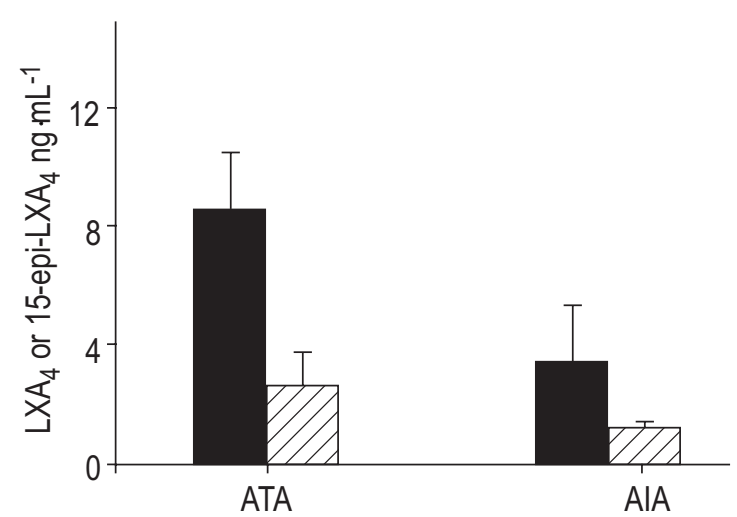

Fig. 2. - Aspirin-intolerant asthmatics (AIA) have a decreased capacity to generate lipoxin (LX) $\mathrm{A}_{4}$ and 15-epimer (epi)-LXA 4 : impact of aspirin. Whole blood from patients with aspirin-tolerant asthmatics (ATA) or AIA was activated (see Methods section) in the presence of lysyl-aspirin $(100 \mu \mathrm{M})$. Values for $\mathrm{LXA}_{4}$ and 15 -epi-LXA 4 were determined by specific enzyme linked immunosorbent assays in tandem (mean \pm SEM). $\mathbf{\square} \mathrm{LXA}_{4} ; \mathbb{Z}: 15$-epi-LXA $\mathrm{LA}_{4}$ 
a)

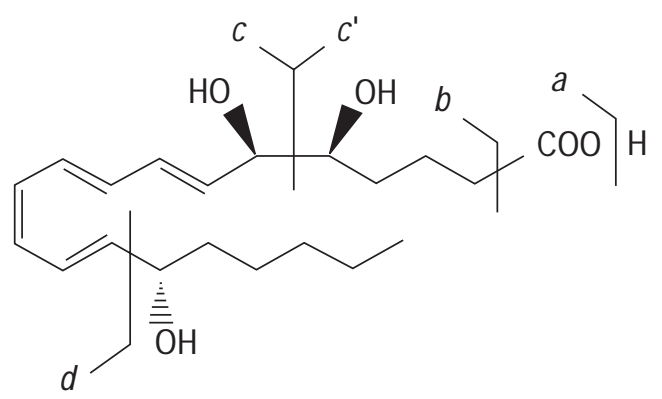

c)

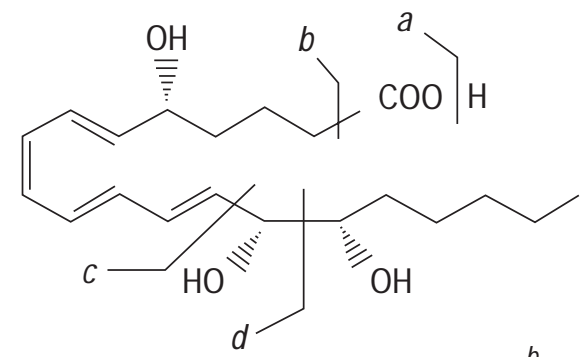
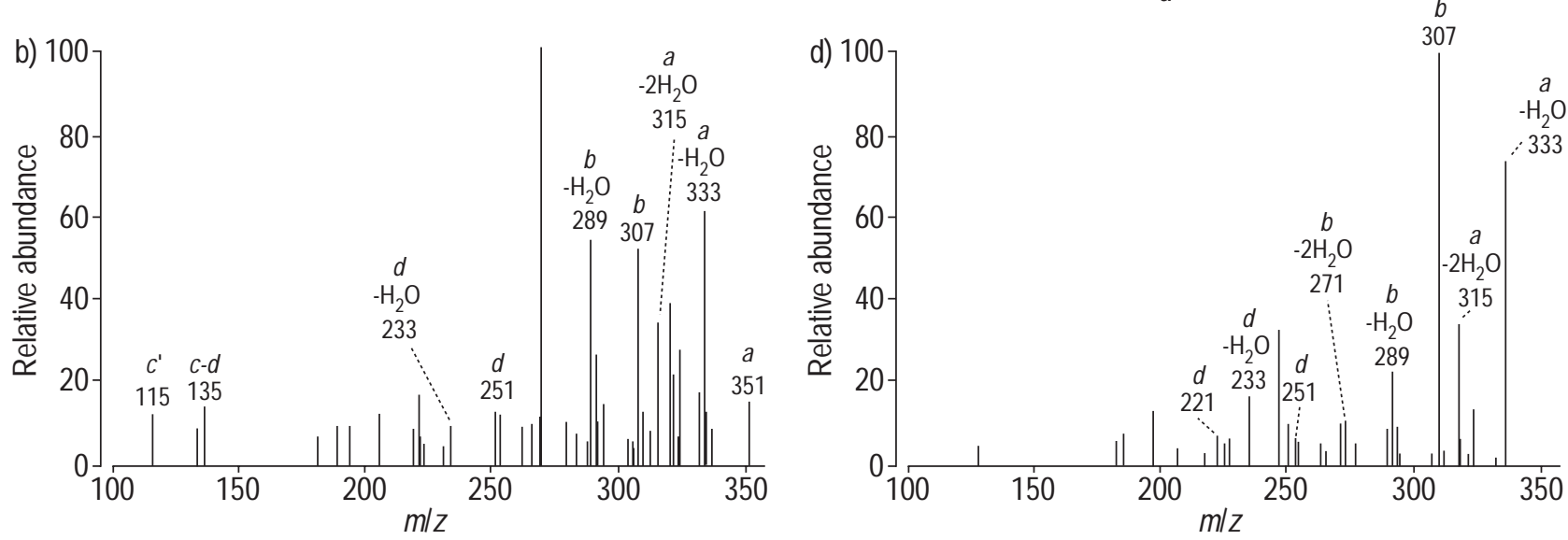

Fig. 3. - Mass spectra and structures of lipoxin (LX)A 4 and $\mathrm{LXB}_{4}$. Product ion mass spectrometry (MS/MS) spectra for LXA $($ a and b) and LXB 4 (c and $\mathrm{d}$ ), which were identified by their ultraviolet spectra and retention times during high-performance liquid chromatography and diagnostic fragmentation in MS/MS, which are highlighted in a and c. Product ion cleavage sites are denoted $a, b, c, c^{\prime}$ and $d$. Diagnostic product ions in the MS/MS spectra of $\mathrm{LXA}_{4}$ (b) were mass-to-charge ratio $(m / z) 351$ (a: molecular anion $\left.[\mathrm{M}-\mathrm{H}]^{-}\right) ; \mathrm{m} / z 333\left(a-\mathrm{H}_{2} \mathrm{O}\right) ; m / z 315\left(a-2 \mathrm{H}_{2} \mathrm{O}\right) ; m / z 307\left(b:[\mathrm{M}-\mathrm{H}]^{-}-\mathrm{CO} 2\right) ; m /$ $z 289\left(b-\mathrm{H}_{2} \mathrm{O}\right) ; m / z 251\left(d:[\mathrm{M}-\mathrm{H}]^{-}-\mathrm{CHO}\left(\mathrm{CH}_{2}\right)_{4} \mathrm{CH}_{3}\right) ; m / z 233\left(d-\mathrm{H}_{2} \mathrm{O}\right) ; \mathrm{m} / z 135\left(c-d:\left[\mathrm{CH}_{2} \mathrm{CH}(\mathrm{CH}=\mathrm{CH})_{3} \mathrm{CHOH}\right]^{-}\right)$, and $\left.m / z 115\left(c^{\prime}: \mathrm{CHO}\left(\mathrm{CH}_{2}\right)_{3} \mathrm{COO}\right)^{-}\right)$. Diagnostic product ions in the MS/MS spectra of $\mathrm{LXB}_{4}(\mathrm{~d})$ were $m / z 333\left(a:[\mathrm{M}-\mathrm{H}]^{-}-\mathrm{H}_{2} \mathrm{O}\right) ; m / z 315\left(a-2 \mathrm{H}_{2} \mathrm{O}\right) ; m / z 307\left(b:\left[\mathrm{M}^{-} \mathrm{H}\right]^{-}-\mathrm{CO} 2\right) ; m / z 289(b-$ $\left.\mathrm{H}_{2} \mathrm{O}\right) ; m / z 271\left(b-2 \mathrm{H}_{2} \mathrm{O}\right) ; m / z 251\left(d:[\mathrm{M}-\mathrm{H}]^{-}-\mathrm{CHO}\left(\mathrm{CH}_{2}\right)_{4} \mathrm{CH}_{3}\right) ; m / z 233\left(d-\mathrm{H}_{2} \mathrm{O}\right)$; and $\left.m / z 221\left(c:\left[\mathrm{M}_{-} \mathrm{H}^{-}-\mathrm{CHOCHOH}^{-} \mathrm{CH}_{2}\right)_{4} \mathrm{CH}\right)_{3}\right)$.

MS/MS system) and was identified by its molecular ion $\left([\mathrm{M}-\mathrm{H}]^{-}=m / z\right.$ 319) and MS/MS ions present at $m / z 301$ $\left([\mathrm{M}-\mathrm{H}]^{-}-\mathrm{H}_{2} \mathrm{O}\right), m / z 275\left([\mathrm{M}-\mathrm{H}]^{-}-\mathrm{CO}_{2}\right), m / z 257\left([\mathrm{M}-\mathrm{H}]^{-}\right.$ $\left.-\mathrm{H}_{2} \mathrm{O},-\mathrm{CO}_{2}\right)$, and $m / z 219$ ([M-H]- $\left.\mathrm{CHO}\left(\mathrm{CH}_{2}\right)_{4} \mathrm{CH}_{3}\right) .15 S-$ HETE is predominantly a $15-\mathrm{LO}$ derived eicosanoid that can serve as a biosynthetic intermediate for LX. Formation of its epimer, $15 R$-HETE, is catalysed by aspirin-acetylated COX-2 and serves as an intermediate in 15-epi-LX biosynthesis $[14,20]$. In contrast to the prominent amounts of $15 S$-HETE present in materials pooled from AIA, levels of $15 R$-HETE in these samples were below the limits of detection for these physical methods and not observed. Not only do these results confirm and extend the antibodybased identification, together they suggest that individuals with AIA accumulate the 15-lipoxygenase product, $15 S$ HETE, but not the aspirin-acetylated COX-2 product, $15 R-$ HETE. This difference is of interest because 15-epi-LX was generated while its precursor $15 R$-HETE, a product of aspirin treatment, apparently was not accumulated in these individuals.

\section{Discussion}

The present results indicate that asthmatic patients can generate both LX and 15-epi-LX (figs. 1 and 2). Of interest, AIA whole blood showed reduced LX and 15-epi-LX biosynthetic capacity and lower ratios for $\mathrm{LXA}_{4}: \mathrm{LTC}_{4}$ generation (figs. 1 and 2) when compared to those values obtained for ATA. Taken together, these results indicate that the ability of asthmatics with AIA to mount "stop signals" (i.e. $\mathrm{LXA}_{4}$ ) is diminished and strikingly different from individuals with ATA.

The first biosynthetic pathway elucidated for LX identified interactions between 15- and 5-LO leading to the sequential insertion of molecular oxygen into the carbon 15 and carbon 5 positions in arachidonic acid [14]. Eosinophils carry prominent 15 -LO activity and can generate LX during cell-cell interactions that occur with leukocytes possessing 5-LO [6]. Eosinophils are enriched in asthmatics [7] and here were present in approximately equal numbers in both ATA and AIA whole blood (table $1)$. Since LX are potent in the picomole to nanomole range in cellular and animal models [14], physiologically relevant amounts of LX can be generated during transcellular eicosanoid biosynthesis.

While aspirin or NSAIDs precipitate symptoms in AIA, individuals with ATA do not experience increased symptoms when challenged with these same agents. In addition to inhibiting COX-catalysed prostanoid formation, the acetylation of COX-2 by aspirin triggers the generation of $15 R$-HETE, a biosynthetic precursor for 15-epi-LX [20]. COX-2 messenger ribonucleic acid was down-expressed in AIA nasal polyps in a study by PIACADO et al. [27], and here 15R-HETE was not detected in aspirin-treated samples from AIA (see Results section). The results shown in figure 2 demonstrate that AIA peripheral blood has diminished biosynthetic capacity for 15-epi-LX, a 5-LO 
product of $15 R$-HETE. Low levels of 15 -epi-LXA 4 were detectable by immunoassay in both AIA and ATA whole blood activated in the absence of aspirin. Only samples from ATA generated increased levels of 15-epi-LXA when stimulated in the presence of aspirin. This reduced 15-epi-LX biosynthetic capacity in AIA may reflect lower COX-2 expression [27], altered COX-2 sensitivity to acetylation by aspirin (for $15 R$-HETE formation) or COX-2 inhibition by asthma medications (e.g., corticosteroids). Since allergic lung responses are heightened in COX deficient mice [28] and 15-epi-LX are more potent than native LX as inhibitors of PMN trafficking and PMNmediated inflammation in vivo [21], generation of 15-epiLX and LX may distinguish the ability of individuals with asthma to tolerate aspirin.

$\mathrm{LXA}_{4}$ and 15-epi-LXA 4 act via the same specific receptor termed ALXR to mediate their counter regulatory actions important in anti-inflammation and resolution of inflammatory sequelae [14]. In addition to ALXR on human leukocytes, $\mathrm{LXA}_{4}$ also interacts in the airway with functionally characterized Cys-LT ${ }_{1}$ receptors $\left(\mathrm{LTD}_{4}\right.$ receptor) to block airway smooth muscle contraction [29]. $\mathrm{LXA}_{4}$ also competes with $\mathrm{LTD}_{4}$ specific binding to endothelial cells in culture [21] and inhibits LTC $_{4}$-mediated airway hyperresponsiveness in asthmatics [13]. $\mathrm{LXA}_{4}$ is rapidly metabolized by isolated leukocytes and several organs, including lung and liver [14]. This observation led to the design of novel LX and 15-epi-LX analogues that are highly bioavailable, metabolically stable and even more potent inhibitors of inflammatory responses in vivo [21]. In view of the present findings, LX and 15-epi-LX analogues may represent a novel strategy for limiting airway hyperresponsiveness and inflammation in AIA and possibly other lung diseases associated with inflammation.

In summary, the present findings indicate that both aspirin-tolerant asthmatics and aspirin-intolerant asthmatics can produce lipoxin and 15-epimer-lipoxin, but when compared to aspirin-tolerant asthmatics and healthy subjects, individuals with aspirin-intolerant asthma show a diminished ability to generate these protective local mediators. It follows that the decreased capacity to form endogenous mediators of anti-inflammation or resolution could facilitate an influx of leukocytes to perpetuate the local inflammatory response and expose bronchial smooth muscle to relatively unopposed actions of bronchoconstricting substances such as cysteinyl leukotrienes [6]. The mechanisms that underlie this diminished lipoxin production were not examined in this initial study and remain the subject for further investigation. Nevertheless, the present results suggest that testing for 15-epimer-lipoxin $\mathrm{A}_{4}$ generation by asthmatics, as documented here, may serve as a convenient means to distinguish between aspirin-tolerant asthmatics and aspirin-intolerant asthmatics and warrants further consideration.

\section{References}

1. Szczeklik A, Stevenson DD. Aspirin-induced asthma: advances in pathogenesis and management. $J$ Allergy Clin Immunol 1999; 104: 5-13.

2. Samter M, Beers RF Jr. Intolerance to aspirin. Clinical studies and consideration of its pathogenesis. Ann Intern Med 1968; 68: 975-983.
3. Kumlin M, Dahlen B, Bjorck T, Zetterstrom O, Granstrom E, Dahlen SE. Urinary excretion of leukotriene $\mathrm{E}_{4}$ and 11-dehydro-thromboxane $\mathrm{B}_{2}$ in response to bronchial provocations with allergen, aspirin, leukotriene $\mathrm{D}_{4}$, and histamine in asthmatics. Am Rev Respir Dis 1992; 146: 96-103.

4. Ortolani C, Mirone C, Fontana A, et al. Study of mediators of anaphylaxis in nasal wash fluids after aspirin and sodium metabisulfite nasal provocation in intolerant rhinitic patients. Ann Allergy 1987; 59: 106-112.

5. Kowalski ML, Sliwinska-Kowalska M, Igarashi Y, et al. Nasal secretions in response to acetylsalicylic acid. $J$ Allergy Clin Immunol 1993; 91: 580-598.

6. Samuelsson B, Dahlen SE, Lindgren JA, Rouzer CA, Serhan CN. Leukotrienes and lipoxins: structures, biosynthesis, and biological effects. Science 1987; 237: 1171-1176.

7. Drazen JM, Israel E, O'Byrne PM. Treatment of asthma with drugs modifying the leukotriene pathway. $N$ Engl $J$ Med 1999; 340: 197-206.

8. Nasser SM, Pfister R, Christie PE, et al. Inflammatory cell populations in bronchial biopsies from aspirin-sensitive asthmatic subjects. Am J Respir Crit Care Med 1996; 153: 90-96.

9. Cowburn AS, Sladek K, Soja J, et al. Overexpression of leukotriene $\mathrm{C}_{4}$ synthase in bronchial biopsies from patients with aspirin-intolerant asthma. J Clin Invest 1998; 101: 834-846.

10. Israel E, Fischer AR, Rosenberg MA, et al. The pivotal role of 5-lipoxygenase products in the reaction of aspirinsensitive asthmatics to aspirin. Am Rev Respir Dis 1993; 148: 1447-1451.

11. Dahlen B, Nizankowska E, Szczeklik A, et al. Benefits from adding the 5-lipoxygenase inhibitor zileuton to conventional therapy in aspirin-intolerant asthmatics. $\mathrm{Am} \mathrm{J}$ Respir Crit Care Med 1998; 157: 1187-1194.

12. Serhan CN, Haeggstrom JZ, Leslie CC. Lipid mediator networks in cell signaling: update and impact of cytokines. FASEB $J$ 1996; 10: 1147-1158.

13. Christie PE, Spur BW, Lee TH. The effects of lipoxin $\mathrm{A}_{4}$ on airway responses in asthmatic subjects. Am Rev Respir Dis 1992; 145: 1281-1284.

14. Serhan CN. Lipoxins and novel aspirin-triggered 15-epilipoxins (ATL): a jungle of cell-cell interactions or a therapeutic opportunity? Prostaglandins 1997; 53: 107-137.

15. Lee $\mathrm{TH}$, Crea $\mathrm{AK}$, Gant V, et al. Identification of lipoxin $\mathrm{A}_{4}$ and its relationship to the sulfidopeptide leukotrienes $\mathrm{C}_{4}, \mathrm{D}_{4}$, and $\mathrm{E}_{4}$ in the bronchoalveolar lavage fluids obtained from patients with selected pulmonary diseases. Am Rev Respir Dis 1990; 141: 1453-1458.

16. Levy BD, Bertram S, Tai HH, et al. Agonist-induced lipoxin $\mathrm{A}_{4}$ generation: detection by a novel lipoxin $\mathrm{A}_{4}-$ ELISA. Lipids 1993; 28: 1047-1053.

17. Edenius C, Kumlin M, Bjork T, Anggard A, Lindgren JA. Lipoxin formation in human nasal polyps and bronchial tissue. FEBS Lett 1990; 272: 25-28.

18. Lee TH, Lympany P, Crea AK, Spur BW. Inhibition of leukotriene $\mathrm{B}_{4}$-induced neutrophil migration by lipoxin $\mathrm{A}_{4}$ : structure-function relationships. Biochem Biophys Res Commun 1991; 180: 1416-1421.

19. Laitinen LA, Laitinen A, Haahtela T, Vilkka V, Spur BW, Lee $\mathrm{TH}$. Leukotriene $\mathrm{E}_{4}$ and granulocytic infiltration into asthmatic airways. Lancet 1993; 341: 989-990.

20. Clària J, Serhan CN. Aspirin triggers previously undescribed bioactive eicosanoids by human endothelial cellleukocyte interactions. Proc Natl Acad Sci USA 1995; 92: 9475-9479.

21. Takano T, Fiore S, Maddox JF, Brady HR, Petasis NA, 
Serhan CN. Aspirin-triggered 15-epi-lipoxin $\mathrm{A}_{4}$ and $\mathrm{LXA}_{4}$ stable analogs are potent inhibitors of acute inflammation: evidence for anti-inflammatory receptors. $J$ Exp Med 1997; 185: 1693-1704.

22. Szczeklik A, Sladek K, Dworski R, et al. Bronchial aspirin challenge causes specific eicosanoid response in aspirin-sensitive asthmatics. Am J Respir Crit Care Med 1996; 154: 1608-1614.

23. Chiang N, Takano T, Clish CB, Petasis NA, Tai H-H, Serhan CN. Aspirin-triggered 15-epi-lipoxin $\mathrm{A}_{4}$ (ATL) generation by human leukocytes and murine peritonitis exudates: development of a specific 15-epi-LXA 4 ELISA. J Pharmacol Exp Ther 1998; 287: 779-790.

24. Young JM, Panah S, Satchawatcharaphong C, Cheung PS. Human whole blood assays for inhibition of prostaglandin $\mathrm{G} / \mathrm{H}$ synthases-1 and -2 using A23187 and lipopolysaccharide stimulation of thromboxane $\mathrm{B}_{2}$ production. Inflamm Res 1996; 45: 246-253.

25. Levy BD, Gronert K, Clish C, Serhan CN. Leukotriene and lipoxin biosynthesis. In: Laychock S, Rubin RP, eds. Lipid second messengers. Methods in signal transduction. Boca Raton, FL, USA, CRC Press LLC, 1999; pp. 83-111.

26. Miura K, Hubbard WC, MacGlashan DW. Phosphorylation of cytosolic phospholipase $\mathrm{A}_{2}$ by IL-3 is associated with increased free arachidonic acid generation and leukotriene $\mathrm{C}_{4}$ release. J Allergy Clin Immunol 1998; 102: 512-520.

27. Picado C, Fernandez-Morata JC, Juan M, et al. Cyclooxygenase-2 mRNA is downexpressed in nasal polyps from aspirin-sensitive asthmatics. Am J Respir Crit Care Med 1999; 160: 291-296.

28. Gavett SH, Madison SL, Chulada PC, et al. Allergic lung responses are increased in prostaglandin $\mathrm{H}$ synthase-deficient mice. J Clin invest 1999; 104: 721-732.

29. Dahlén S-E, Serhan CN. Lipoxins: bioactive lipoxygenase interaction products. In: Wong A, Crooke ST, eds. Lipoxygenases and their products. San Diego, CA, USA, Academic Press, 1991; pp. 235-276. 